\title{
Golden Opportunity, Reasonable Risk and Personal Responsibility for Health
}

In her excellent and comprehensive article, Friesen argues that utilising personal responsibility in health care is problematic in several ways: (1) it is difficult to ascribe responsibility to behaviour; (2) there is a risk of prejudice and bias in deciding which behaviours a person should be held responsible for; (3) it may be ineffective at reducing health costs. In this short commentary, I will elaborate the critique of personal responsibility in health but suggest one way in which it could be used ethically. In doing so, I will introduce the concepts of reasonable risk and golden opportunity.

I previously argued that it is both difficult to disentangle responsibility and that we risk prejudice and bias in singling out behaviours that are socially disapproved of [1] . So I am sympathetic to Friesen's concerns.

I also discussed another way in which ascribing personal responsibility for health is problematic which Friesen does not discuss and which, in my view, is the most concerning and further supports her arguments. It represents a back door assault on liberalism and neutrality towards concepts of the good life. Even if one were to accurately and in an unbiased way divine the personal contribution to disease, the greatest problem would remain: those who voluntarily take on risk would be penalised. That is, such a system would be risk-averse. Those lives which avoided risk would be prioritised, while those who chose to take on risky activities in their conception of the good life would be penalised. Yet risk is necessary, both for the good life, and social progress.

Columbus, Edmund Hilary, Ernest Hemingway and countless monumental figures in human history took risks in order to achieve something great. Should we aim for society of trembling, teetotalling health nuts? Surely that prospect is horrific. It is horrific because it elevates health above all aspects of well-being and value. It is an example of health totalitarianism, or at very least, health fetishism.

Living well requires taking risks. And we should not necessarily encourage people to be maximally risk averse. The real problem with internalising the costs of behaviour is that it incentivises risk aversion. It leads to lives which are boring and uninspiring.

This indirect contraction of the range of good lives available to people which comes from holding people responsible for their health is the most worrying aspect of such a proposal. We should be free, as Mill put it, to engage in experiments in living - and those experiments have risks.

The real issue is not eliminating risk, but settling on what constitutes a reasonable risk. 


\section{Reasonable and Unreasonable Risk}

Consider the behaviours that Friesen divides into cases which are typically considered in the literature and those which are unconsidered [2]. Considered cases include smoking, drinking, drug use, poor eating habits and attempted suicide. She includes within unconsidered cases "extreme sports, elective surgeries, motorcyclists, etc." [2] The "etc" here is actually very large - it includes any activity with a foreseeable, avoidable risk which the individual chooses voluntarily to engage in.

There are various ways in one could try to justify this distinction. These include: 1. size of the probability of harm is greater in the considered cases than in the unconsidered cases.

2. expected harm (probability of harm multiplied by magnitude).

3. social disapproval or stigma [3]

4. total financial cost to society of that activity as a whole.

There is not space to consider these in detail but I believe all fail to provide a sufficient justification for distinguishing between those risks for which an individual ought to be held accountable within a responsibility-sensitive scheme of allocation of resources, and those for which they should not be.

The reason for this is that we must consider not only the expected harm of an activity, but its expected benefit in order to value it. Food and pharmacologically active substances (alcohol, nicotine and recreational drugs) have many benefits. For example, Faden and colleagues defend the social value of eating food, @as a way to express love, forge relationships, and reinforce bonds". They argue that food should be seen in its community as well as individual context: "Specific foods or food traditions have cultural and religious significance, and a special place in family and community life" [4] . The problem is, when consumed in certain ways and in certain amounts, food, nicotine and drugs have harmful effects. When the expected benefits outweigh the expected harms, their consumption is reasonable. When the risks grossly outweigh the benefits, their consumption is unreasonable.

What distinguishes the two lists is that most of the behaviours on the considered list involve unreasonable risks and most of those on the unconsidered side involve reasonable risks.

For example, smoking tobacco is an unreasonable risk because the benefits of the drug nicotine and ritual of smoking can be obtained using ecigarettes, with significantly lower risks. It is irrational to smoke cigarettes. [5]

Having an elective caesarean section is a reasonable risk as it avoids many of the risks of injury during delivery to the mother and fetus, though it is associated with surgery-specific risks. It is not clearly inferior, and maybe superior, to normal vaginal delivery. Whether one is "better" than the other is not necessarily that important (from the perspective of interests) because the expected value of each are reasonably closely matched. 
Compare this to homebirth for a complicated pregnancy (eg breech) after a complicated previous pregnancy. The risks here are considered unreasonable. [6]

Cycling has greater risks than public transport. However, the health benefits, pleasure and social benefit (including environmental benefit) reasonably balance these risks.

Other cases are not clear cut and warrant discussion, such as riding a motorcycle. I am inclined to think the risks here reasonable, though not risks I would personally take.

\section{Deciding Reasonableness of Risk}

As I have argued in the context of research participation [7, 8] and health care[9], it is not risk per se which is important - many worthwhile activities have significant risks - but the reasonableness of risk which is key, that is, whether the risk is worth taking.

How are we to decide on the reasonableness of risk?

Not by just asking the individuals concerned. This would be a purely subjective approach to risk. According to such a standard, riding a motorbike at $80 \mathrm{mph}$ with a BAC of 0.1 would be a reasonable risk if the individual deemed it so. Presumably some would. Some people are reckless. Laws are created to regulate reckless behaviour.

What matters in assessing the reasonableness of risk is the objective value of the activity and its harms, as well as the probability of them occurring. Society is entitled to set a limit on what it considers reasonable. The following factors are relevant to determining the reasonableness of risk [8]:

1. There should be a favourable cost-benefit ratio. Costs and benefits should be measured in terms of impact on well-being. Well-being should be conceived of in terms happiness and objectively valuable activity. Objectively valuable aspects of well-being include: depth and breadth of social relationships, development of talents, gaining knowledge, achieving worthwhile things, appreciating beauty, etc. $[10,11]$

2. The evidence for probability and nature of outcomes of activities should be proportionate to costs and benefits involved. The greater the potential risks, the stronger the evidence ought to be.

3. Risk should be minimized to the smallest degree necessary for the relevant benefits.

4. We should have sufficient information to make a decision. That is, further information gathering (further research, modelling or other investigation) should not justified in terms of opportunity costs.

5. Some consideration should be taken of individuals' own autonomous desire to pursue the activity in question. The more important something is to us, the more 
it is worth taking risks for it. Autonomy should be conceived not in as the mere desire of a competent person, but as rational desire $[9,12]$

6. Considerations of justice and impact on others should be included. It can be reasonable to die for the sake of others: examples include "dying for one's country" in war, or through organ donation euthanasia [13], or participation in risky research which may lead to improved treatments for others [14].

\section{Control and Freewill: Golden Opportunity}

Establishing some risk is unreasonable is not yet to say a person has responsibility, in the sense of responsibility for which he might be held accountable in the allocation of health resources. One also has to show that a person has sufficient control over their behaviour. As Friesen well points out, the degree of responsibility a person has for her behaviour is difficult to assess. Upbringing, peer group pressure, and perhaps genetic factors predisposing to addictive behaviour may combine to make a particular individual vulnerable to smoking. Furthermore, she may have become addicted to smoking when she was a teenager.

As Friesen notes, the "social determinants of health" movement has called into question how much control individuals have over their behaviour and the lifestyles which contribute to their disease. As a matter of policy, it would be impracticable and extraordinarily expensive to try to work out, if it were even possible, how much control an individual had over his or her life that led to the health-damaging behaviour in question.

A more promising route is to look at prospective responsibility: enabling individuals to take responsibility for their behaviour under controlled conditions. If we give individuals a reasonable opportunity to take responsibility, and they choose not to, then we can then hold them (retrospectively) responsible for the consequences.

Consider an analogy. Imagine a group of "mature minors", sixteen year olds deemed capable of taking responsibility for their behaviour. They are doing a home economics subject. Their teacher sets them the task of baking a cake for homework. The next day, all the cakes will be shared.

Now if several students understand this and nonetheless choose to spend their evening on social media and fail to bake their cake, they are responsible for that failure. Provided they had adequate time, opportunity and resources to bake their cake, and they chose not to, they are responsible for not having a cake to take to school. The teacher would be well within her rights not allow them to share in the cakes provided by the other students, even if their eating some cake would maximise overall utility.

They don't deserve cake; they are free riders.

This example is disanalogous to most ordinary situations where people are asked to take responsibility for their health. For example, when an individual is 
told to give up smoking or lose weight before surgery, they may not have "adequate time, opportunity and resources" to engage in lifestyle change.

To be sure, there are quit campaigns available that offer support, and various weight loss programmes, and other supportive programmes. It is not my purpose to argue whether or not such programmes give addicted individuals a realistic and reasonable chance of changing their behaviour. Let's call an offer which does give an individual an realistic and reasonable opportunity for change a golden opportunity.

A golden opportunity, then, is an offer of lifestyle which has:

(1) either:

a. the same valuable activities, but fewer risks

b. greater objective value, but the same risks, as the existing lifestyle. and (2) is realistically adoptable.

Consider an example of a golden opportunity. Jim has severe emyphysema or chronic obstructive airways disease. In about a year, it will have progressed to Jim requiring a lung transplant. Jim has been a 40 a day smoker all his life. He grew up in a poor deprived environment and all his family and friends smoked. Jim has found it impossible to quit on current programmes.

Jim's doctors realise it is going to be very difficult if not impossible for Jim to quit but if he continues to smoke, this will jeopardise both his survival and the chances of his lung transplant succeeding. So they give him a golden opportunity: switch to smoking e-cigarettes.

E-cigarettes have the active drug - nicotine - which conventional cigarettes have. yet they have vastly reduced health risks [15] though these have not been fully documented in the long term. The ritual element of smoking can be achieved by vaping, and imitation cigarettes look and behave much as tobacco-laden alternatives.

Let's assume e-cigarettes fulfil the criteria for a golden opportunity. Jim would get "to have his cake and eat it too". That is, he could continue to enjoy all or most of the benefits of smoking, with virtually none of the risks. In addition, he would save money. Now imagine that e-cigarettes were provided at an even lower price, and professional and peer support established to facilitate the transition to vaping.

If Jim chose not to switch from tobacco to e-cigarettes, he would be responsible for that choice. Because the choice has been set up in a way to maximise choosability, we can at this point, if we can at any point, say that Jim is responsible for his behaviour. It would then be reasonable to give Jim a lower priority for a lung transplant than someone who had chosen to take the golden opportunity, though he might receive a transplant if no other suitable recipient were available. 
Other examples of golden opportunities might be methadone replacement therapy, or highly supported health camps with portion controlled diets of nutritious, tasty food in conjunction with personal exercise training. Whether and what golden opportunities do exist, or could exist in a world of limited resources, is beyond the scope of this paper. The point is - if an individual chooses to forgo a golden opportunity, that individual fails to take responsibility in the prospective sense and can be held accountable for that choice, even if he can't be held responsible for choosing or perpetuating the lifestyle up to the point of being offered the golden opportunity.

You might think that such a proposal disadvantages the worst off. That is, those with the least self control, with mental illness, a history of abuse, etc are not going to have it in them to choose the obviously better alternative, no matter how much support.

Though the worst off may have less scope for choice than others, it is implausible that they can't choose golden offers. Only people incapable of exercising choice at all would lack the capacity to choose these offers, given how they are constructed. If people are incapable of exercising choice at all, then they lack autonomy and might appropriately be subject to paternalistic control. If that is the case, the government should legislate to coerce people to live good lives. They would not be freely choosing the bad. If people were not able to move from tobacco to e-cigarettes with reasonable support, this would argue in favour of banning tobacco cigarettes.

Finally, it is a familiar critique of objectivism about value and "positive liberty" that it invites authoritarianism about value and conceptions of the good [16]. It is of course a danger that the range of conceptions of the good is unreasonably narrowed. But it is reasonable and justifiable for society to say that vaping is better than smoking, because it has all or most of the benefits with far fewer risks. That is why Cancer Research UK is promoting it [15]; that is why Public Health England promotes it [17]. At some point, we have to get off the fence about whether relativism and subjectivism are suitable ways to organise a health system, or a society. I believe they are not.

It is difficult to hold individuals responsible for their past behaviour. But it is possible to give individuals structured, controlled programmes to change their behaviour for the better. Where such programmes constitute a golden opportunity, individuals can be held responsible for not taking them. If responsibility is to have a place in the allocation of limited health care resources, it is this controlled sense of prospective responsibility which is fit for purpose. It is dependent on whether they have a golden opportunity to change. We can judge the reasonableness of risk and our task is to construct golden opportunities for objectively better lives. Freedom is important to choose amongst worthwhile options, not meaningless or bad options.

\section{References:}

[1] Savulescu, J. Warning : smoking harms your chances, Australian Medicine, 2001, Mar; 13(4):10. 
[2] Friesen P. Personal responsibility within health policy: unethical and ineffective Journal of Medical Ethics Published Online First: 22 September 2016. doi:

10.1136/medethics-2016-103478

[3] Ubel PA. Transplantation in alcoholics: separating prognosis and responsibility from social biases. Liver Transp/ Surg 1997;3:343-6. Quoted in Friesen, p. xxx

[4]Barnhill, A., King, K., Kass, N., Kennedy, R., Faden, R., The Value of Unhealthy Eating and the Ethics of Healthy Eating Policies. Kennedy Institute of Ethics Journal, 2014: 24 (3):187-

217

[5] Public Health England . ECigarettes: A Firm Foundation for Evidence Based Plicy and Practice.

https://www.gov.uk/government/uploads/system/uploads/attachment data/file/454517/E cigarettes a firm foundation for evidence based policy and practice.pdf 2015

[6] National Institute for Health and Care Ecellence 2014. Intrapartum care for healthy women and babies Clinical guideline [CG190] https://www.nice.org.uk/guidance/CG190

[7] Savulescu, J. Safety of Participants of Non-Therapeutic Research Must be Ensured. British Medical Journal 1998;316: 891-2.

[8] Savulescu, J. and Hope, T. Ethics of Research. In Skorupski, J. editor. The Routledge Companion to Ethics . Abingdon: Routledge, 2010. pp. 781-795.

[9] Savulescu, J. Autonomy, the Good Life, and Controversial Choices In: . Rhodes, R., Francis, L.P., and Silvers, A. eds The Blackwell Guide to Medical Ethics. Oxford: Blackwell Publishing, 2007 pp. $17-37$.

[10] Parfit, D. Reasons and persons. Oxford: Oxford University Press; 1984.

[11] Griffin J. Wellbeing: Its Meaning, Measurement, and Moral Importnace. Oxford: Clarendon Press; 1986

[12] Savulescu, J. Rational Desires and the Limitation of Life-Sustaining Treatment. Bioethics. 1994; 8: 191-222.

[13] Wilkinson, D., and Savulescu, J. Should We Allow Organ Donation Euthanasia? Alternatives for Maximizing the Number and Quality of Organs for Transplantation. Bioethics 2012; 26:1: 32- 48.

[14] Halpin L, Savulescu J, Talbot K, et al Improving access to medicines: empowering patients in the quest to improve treatment for rare lethal diseases Journal of Medical Ethics 2015;41:987-989.

[15] Cancer Research UK. Cancer Research UK Briefing: Electronic Cigarettes. 2016 http://www.cancerresearchuk.org/sites/default/files/e-

cigarette briefing nov 2016 final.pdf. Accessed 8 June 2017. 
[16] Berlin, I. Two concepts of liberty: an inaugural lecture delivered before the University of Oxford on 31 October 1958. Oxford: Clarendon Press; 1958.

[17] Public Health England. E-cigarettes: a new foundation for evidence-based policy and practice 2015.

https://www.gov.uk/government/uploads/system/uploads/attachment data/file/454517/E cigarettes a firm foundation for evidence based policy and practice.pdf. Accessed 8 June 2017. 